\title{
Talks start on policing bio-weapons ban...
}

[PARIS] Prospects for adding a verification regime to the worldwide ban on the production, possession and use of biological weapons edged a step closer last week. Talks opened in Geneva on a 'rolling text' that will form the basis of negotiations.

But industries using biotechnology and genetic engineering techniques, which are coming under increasingly close scrutiny from arms control agencies, are concerned that compliance could lead to extra regulations and loss of confidential information.

Awareness has grown recently of the need to reinforce the 1975 United Nations Biological Weapons Convention (BWC) with measures to deter and detect cheats. For example, although the former Soviet Union was one of the sponsors of the convention, it has admitted running a covert weapons programme until 1992, while the Gulf War revealed that Iraq possessed biological weapons.

The lack of a verification protocol in the convention "is one of the main weaknesses in the international regime against weapons of mass destruction," says Graham Pearson, former head of the UK Chemical and Biological Defence Establishment at Porton Down. Pearson points out that both the Chemical Weapons Convention agreed earlier this year and the Nuclear Non-Proliferation Treaty have strict verification regimes.

The preliminary rolling text was prepared by four working groups for an ad hoc committee of around 50 countries chaired by Tibor Tóth, Hungarian ambassador to the United Nations, and remains confidential. But it is believed to provide only a skeleton for the protocol, with most of the text yet to be agreed. Flesh will be added during the current talks which end on 1 August, and in a further round in September, before negotiations on the details begin in earnest next year. A conference of the BWC countries is expected to be held in 1999 to adopt the protocol.

The text's provisions include mandatory declaration of all sites of most relevance to the convention, and the means to launch investigations of suspected facilities and incidents. These measures would be enforced by a permanent international secretariat. Provisions would apply to all relevant civil and military research and production centres, including those of the pharmaceutical and biotechnology industries.

Few believe that biotechnology companies in democratic countries would risk working on weapons, but submitting them to strict controls is seen as the price of a protocol that will allow checks on military installations and rogue countries. Site inspections and removal of samples could threaten commercial confidentiality, however, warns EuropaBio, a trade organization representing 600-plus European companies.
Andrew Dickson, its secretary general, says that the industry nonetheless "recognizes the need for a verification regime," and will work to find amicable solutions.

The Association of Pharmaceutical Research and Manufacturers of America (PhRMA) says it wants to work "to reduce the threat of biological warfare". But it will "oppose any protocol that does not fully protect confidential business information".

PhRMA says it is opposed to routine inspections, arguing that inspections should be permitted only in response to specific allegations of violations of the BWC. It says inspections should be authorized only after a majority vote by an executive council of government representatives.

The task of overcoming industrial concerns should be eased by the experience gained during negotiation of the Chemical
Weapons Convention (CWC), says Martin Kaplan, director of the Geneva office of Pugwash. One compromise in the CWC was the concept of "managed access", which allowed an inspected state to propose alternative means of demonstrating compliance, for example by offering spot checks on some but not all parts of an installation, but with the choice of which remaining with the inspectors. Another idea being floated is to forgo removal of samples during inspections, with all analyses being carried out on-site.

Kaplan says a major stumbling-block in the negotiations will be the financing of the verification regime, which could cost US\$100 million annually. Developing countries are also expected to hold agreement of the protocol hostage to obtaining technology transfer agreements on biotechnology from industrialized nations.

DeclanButler
[PARIS] A major spur to efforts to strengthen the Biological Weapons Convention is mounting concern about the spectre of 'designer' biological weapons. Experts are divided over the extent to which such weapons pose a realistic threat. But there is widespread consensus that the convention and verification measures need to discourage any attempts to develop them.

There are two broad classes of designer weapons: biotechnological weapons, where an organism's characteristics are modified to enhance its military potential, and genetic weapons that could target genetic differences between populations.

Concern about such weapons crystallized at the convention's fourth review conference in Geneva last winter. Although such weapons are prohibited under the general wording of the convention, the conference felt it necessary to extend this explicitly to include applications arising from "molecular biology" and "genome studies".

Concern about designer weapons has also recently been expressed by the
International Committee of the Red Cross, the Federation of American Scientists and the World Medical Association.

Vivienne Nathanson, head of science and ethics at the British Medical Association, says that, as genome research is aimed at finding targeting systems for drugs, such knowledge could also be used to inflict damage. "The potential for weaponization of that knowledge is significant," she says.

Weapons based on genetic manipulation - for example to enhance toxin production - are considered by many to be a realistic, if remote, threat. "It's not difficult to imagine pathogenicity being engineered into an organism, while designing an antidote specifically for your own troops," says Jean Pascal Zanders of the Stockholm International Peace Research Institute.

But genetic weapons are dismissed by many weapons experts as science fiction. The technical feasibility of developing them "cannot be discounted, but at this stage it is bunk," says Matthew Meselson of the Department of Molecular and Cellular Biology at Harvard University, an expert on chemical and biological weapons.

Meselson is also sceptical that militarily useful genetic differences could be identified, pointing out that ethnic differences are often based on culture, not on genetics. At worst such weapons would "preferentially harm one group over another," he says.

Would-be proliferators are also likely to be discouraged from using designer weapons because they would need to be extensively tested in the field, says Graham Pearson, former head of the UK Chemical and Biological Defence Establishment.

The risk of designer weapons should nonetheless "not be downplayed", warns Barbara Hatch Rosenberg, a microbiologist at the State University of New York at Purchase and chair of the Federation of American Scientists' Chemical and Biological Weapons Program. "I think the risk should be taken seriously," she says, adding that the convention should take such risks into account. 